\title{
The challenge of diagnosing dengue in children
}

\author{
Susie Andries Nogueira*
}

D engue is the most common arbovirus worldwide, it is one of the most frequent causes of hospitalization and death of children in endemic areas and it is estimated that 50 to 100 million cases of dengue occur each year and 250,000 to 500,000 cases of dengue hemorrhagic fever (DHF) worldwide. During 2002, more than 30 Latin American countries reported 1 million cases of dengue, DHF occurred in 20 countries with more than 17,000 notified cases, including 225 deaths. In the Americas, DHF is observed in adults and children, and secondary infection by another serotype of the dengue virus has been confirmed as an important risk factor for this severe form of the disease. ${ }^{1}$

A recent study by the Health Ministry, ${ }^{2}$ analyzing dengue and DHF data from 1980 to 2002, states that three serotypes (1,2 and 3 ) are currently co-circulating in 22 of the 27 Brazilian States and that, although adults are the most affected, there is an increase of DHF in children taking place in the North of Brazil, which suggests that the more severe forms are extending to younger age groups. In the current issue of the Jornal de Pediatria, the excellent article done by Rodrigues et al., ${ }^{3}$ discusses the low sensitivity and specificity of the Health Ministry's criteria for suspected dengue cases. ${ }^{4}$ It has long been known that asymptomatic or oligosymptomatic forms of dengue occur more often in children ${ }^{5,6}$ and this study, performed at a public outpatients unit in Belo Horizonte and involving children with nonspecific febrile conditions clearly demonstrates that children with a confirmed serological diagnosis of infection by the dengue virus might well not be diagnosed if their cases were assessed exclusively based on the Ministry's criteria. Only the presence of exanthema was shown to have a significant relation with a laboratory diagnosis of dengue, but, since exanthema is described in less than $1 / 3$ of dengue cases, 5 this is undoubtedly not a particularly sensitive indicator for diagnosing this viral infection. It is interesting that the study was conducted during two distinct periods with different prevalence rates for the disease, providing evidence that the Health Ministry criteria is more sensitive during epidemic * PhD. Pediatrician and infectologist, Health Department of the city of
Petrópolis. Professor, School of Medicine, Petrópolis, RJ, Brazil.

Suggested citation: Nogueira SA. The challenge of diagnosing dengue in children. J Pediatr (Rio J). 2005;81:191-2. periods, demonstrating that its predictive value increases with disease frequency. Since no sample size calculation was performed for this study, doubt remains as to whether, if the number of patients studied had been greater, there would perhaps have been a statistical association with other signs or symptoms, thus increasing the sensitivity and predictive value of the Health Ministry criteria. Nevertheless, similar findings have been described by other authors in several different areas where dengue occurs, that is to say, the lack of specificity of dengue manifestations in children, in particular the youngest ones. ${ }^{7}$ Among the patient sample analyzed in this article there were no cases of DHF, which suggests that the results are applicable to less severe cases of dengue. If blood smears with platelet counts had been performed for these children before laboratory confirmation of dengue, perhaps the diagnostic sensitivity could have been increased by using this simple test together with the clinical signs and symptoms suggested by the Health Ministry.

On the other hand, the DHF classification proposed by the World Health Organization is also questioned by some authors. A recent study in Vietnam ${ }^{8}$ of 712 children with dengue infections disputes the precision of the DHF classification for differentiating classic dengue from DHF and point out that petechiae, thrombocytopenia and a positive tourniquet test weakly differentiate these two clinical entities. In this study, $18 \%$ of the 310 patients who suffered shock did not exhibit the four criteria for DHF. In a recent epidemic in Mumbai, ${ }^{9}$ India, children with clinical suspicion of dengue were prospectively analyzed over three months and 39 of them were confirmed serologically. The median age was 4.9 years and since these were more severe cases that had been admitted to a children's hospital, 20 were diagnosed with DHF and 18 presented with shock. Fever, hepatomegaly, vomiting, bleeding, rash erythematosus, thrombocytopenia and increases in hepatic enzymes, were the primary findings. Markers for predicting shock were low age, sensory alterations, paralytic ileum and abnormal prothrombin times.

Dengue continues to be a diagnostic challenge, particularly in children and because we do not yet have effective immunization or specific anti-viral treatment, fighting the disease is limited to controlling its vector and treatment of symptoms. Finally, these study emphasizes 
the importance of seeking a laboratory diagnosis of the etiology of acute febrile diseases with nonspecific symptoms in pediatric patients, particularly in areas where dengue occurs, in order to quickly diagnose epidemic outbreaks and prevent and/or treat quickly (teaching mothers the "warning signs") the severe forms and complications and reduce the morbidity and lethality of this arbovirus among the child population.

\section{References}

1. Guzman MG, Kouri G. Dengue and dengue hemorrhagic fever in the Americas: lessons and challenges. J Clin Virol. 2003;27:1-13.

2. Siqueira JB, Martelli CM, Coelho GE, Simplicio AC, Hatch DL. Dengue and dengue hemorrhagic fever, Brazil, 1981-2002. Emerg Infect Dis. 2005;11:48-53.
3. Rodrigues $M B$, Freire HB, Corrêa PR, Mendonça ML, Silva MR, França EB. É possível identificar a dengue em crianças a partir do critério de caso suspeito preconizado pelo Ministério da Saúde? J Pediatr (Rio J). 2005;81:209-15.

4. Ministério da Saúde. Fundação Nacional de Saúde (FUNASA). Dengue: diagnóstico e manejo clínico. Brasilia: Fundação Nacional de Saúde; 2002. 28p.

5. Nogueira SA. Dengue. J Pediatr (Rio J). 1999;75 Supl 1:S9-14.

6. Nogueira SA. Dengue. In: Farhat CK, Carvalho ES, Carvalho LH, Succi RC. Infectologia pediátrica, $2^{a}$ ed. Atheneu: São Paulo; 1998. p. 378-382.

7. Kalayanarooj S, Nimmannitya S. Clinical presentation of dengue hemorrhagic fever in infants compared to children. J Med Assoc Thai. 2003;86 Suppl 3:S673-80.

8. Phuong CX, Nhan NT, Kneen R, Thuy PT, Thien CV, Nga NT, et al. Clinical diagnosis and assessment of severity of confirmed dengue infections in Vietnamese children: is the World Health Organization classification system helpful? Am J Trop Med Hyg. 2004;70:172-9.

9. Shah I, Deshpande GC, Tardeja PN. Outbreak of dengue in Mumbai and predictive markers for dengue shock syndrome. J Trop Pediatr. 2004;50:301-5. 